\title{
TESTE DE PELE EM CAPRINOS VACINADOS E INFECTADOS COM CORYNEBACTERIUM PSEUDOTUBERCULOSIS ${ }^{1}$
}

\author{
FRANCISCO SELMO FERNANDES ALVES ${ }^{2}$ e HARVEY JOHN OLANDER ${ }^{3}$
}

\begin{abstract}
RESUMO - Dez caprinos foram vacinados com toxóide a 3\%, outros dez com uma bacterina e mais dois grupos-controle de cinco animais cada, submetidos à inoculação de infusão de cérebro e coração e solução salina, respectivamente. Todos os animais foram examinados e avaliados com um teste de pele. Tanto o toxóide quanto a bacterina foram produzidos a partir de amostra de Corynebacterium pseudotuberculosis. Todos os caprinos foram desafiados com C. pseudotuberculosis, trinta dias após as vacinações. Nenhuma das vacinas induziu reação de hipersensibilidade na pele dos caprinos antes do desafio. Após o desafio, todos os animais desenvolveram reações mensuráveis na primeira, quinta e décima semana em resposta ao teste de pele. Os diâmetros da reação dérmica aumentaram do décimo dia à quinta semana após o desafio. As medidas alcançaram tamanho maior na décima semana. O resultado deste estudo indica que antígeno específico do C. pseudotuberculosis pode ser utilizado em caprinos no diagnóstico da linfadenite caseosa como teste de pele ou como instrumento experimental para monitorar o desenvolvimento da doença.
\end{abstract}

Termos para indexação: diagnóstico, teste intradérmico, imunidade celular, antígeno, doença subclínica.

\section{SKIN TEST OF GOATS VACCINATED AND INFECTED \\ WITH CORYNEBACTERIUM PSEUDOTUBERCULOSIS}

\begin{abstract}
Ten goats were vaccinated with a $3 \%$ toxoid, ten vaccinated with a bacterin and two control groups (five animals each) inoculated with brain heart infusion and saline solution, respectively. All animals were skin tested with a crude antigen of formalin-killed Corynebacterium pseudotuberculosis bacterial cells. All goats were challenged with a virulent C. pseudotuberculosis thirty days after vaccination. Neither the vaccinated nor control goats responded to the skin test prior to infection. After the challenge, dermal reactions were demonstrated in all animals at one week, five and ten weeks. The diameters increased from the first week, five and ten weeks. The reactions were more proeminent at ten weeks. The results of this study indicate that skin testing with a specific bacterial antigen of $C$. pseudotuberculosis may be useful in goats for field diagnosis of caseous lymphadenitis or as an experimental tool to monitor progress of the disease.
\end{abstract}

Index terms: diagnostic, intradermic test, cell immunity, antigen, subclinical disease.

\section{INTRODUÇÃO}

A linfadenite caseosa (LC) é uma doença infectocontagiosa, causada pelo Corynebacterium

\footnotetext{
${ }^{1}$ Aceito para publicação em 2 de setembro de 1998.

${ }^{2}$ Méd. Vet., Ph.D., Embrapa-Centro Nacional de Pesquisa de Caprinos (CNPC), Estrada Sobral/Groaíras, Km 04, Caixa Postal D-10, CEP 62011-970 Sobral, CE. E-mail: selmo@cnpc.embrapa.br

${ }^{3}$ Méd. Vet., Ph.D., Dep. de Microbiologia, Imunologia e Patologia Veterinária, Universidade da Califórnia, Davis, 95616 - Davis, Califórnia.
}

pseudotuberculosis, que acomete caprinos e ovinos, e caracterizada pela formação de abscessos superficiais ou viscerais. No diagnóstico desta enfermidade, diversos testes sorológicos e alérgicos têm sido recomendados (Costa Filho, 1977/78; Langenegger \& Langenegger, 1984; Brown et al., 1986; LeaMaster et al., 1987; Laak et al., 1992); entretanto, faz-se necessária a avaliação e o uso prático desses testes no campo. Os ensaios sorológicos utilizados são baseados na resposta imune humoral para a exotoxina e células completas de C. pseudotuberculosis, demonstrando variação em 
sua precisão (LeaMaster et al., 1987; Laak et al., 1992). O teste sorológico ELISA e o imunoblot têm mostrado maior sensibilidade ao detectar anticorpos para a exotoxina, ao invés de células completas (Laak et al., 1992). O teste de pele é um método de diagnóstico usado para verificar infecções causadas por microrganismos intracelulares; é também usado para medir o estado imunológico mediado por células, principalmente em doenças causadas pelas bactérias $C$. pseudotuberculosis e Mycobacterium spp. Essas bactérias são microrganismos intracelulares facultativos (Hard, 1975), com imunidade mediada por células, daí o uso do teste de pele ser importante no diagnóstico de infecções causadas por elas. A imunidade mediada por células induz a formação de uma população de células mononucleares especializadas em fagocitar e destruir esses microrganismos intracelulares (Mackaness, 1970). Em caprinos e ovinos, naturalmente e artificialmente infectados com C. pseudotuberculosis, a tuberculina mostrou reação cruzada não específica, provavelmente em decorrência de antígenos comuns da parede celular (Shukla et al., 1971). Renshaw et al. (1979), usando células sonicadas de $C$. pseudotuberculosis em um grupo de ovelhas com lesões de linfadenite visceral, observaram que o nível de reação dérmica foi baixo (56\%), provavelmente devido ao estado de imunossupressão decorrente da doença disseminada. Também, Langenegger et al. (1987) utilizaram um alérgeno em 40 caprinos, que consistia de proteína hidrossolúvel, extraída a partir de células lavadas do C. pseudotuberculosis, e conhecida como linfadenina. Usando este alérgeno em grupos de caprinos portadores e grupos sadios, encontraram diferença entre as respostas dos animais doentes e sadios, demonstrando assim resultados promissores.Verifica-se que é essencial contar com meios de diagnóstico para a linfadenite caseosa, mesmo na infecção subclínica, e que sejam de fácil aplicação. Este trabalho teve como objetivo verificar a utilidade do teste de pele em caprinos vacinados e infectados com C. pseudotuberculosis.

\section{MATERIAL E MÉTODOS}

A amostra de C. pseudotuberculosis usada no experimento foi obtida de um abscesso em caprino naturalmente infectado. O isolamento e a identificação da bactéria foram realizados no Laboratório de Diagnóstico Microbiológico do Hospital de Medicina Veterinária da Universidade da Califórnia, em Davis. Utilizaram-se trinta animais da raça pardo alpina, com idade de cinco meses, os quais foram casualmente separados em quatro grupos: grupo I, dez animais vacinados duas vezes com toxóide a 3\%; grupo II, dez animais vacinados duas vezes com bacterina; grupo III, controle, cinco animais submetidos à inoculação de meio de infusão de cérebro e coração; e grupo IV, controle, cinco animais submetidos à inoculação de solução salina. Todas as vacinações foram realizadas por via subcutânea, com intervalo de duas semanas. O toxóide a $3 \%$ e a bacterina foram produzidas a partir da amostra isolada de C. pseudotuberculosis, segundo Alves (1988). O antígeno para o teste de pele foi preparado de acordo com o método descrito por Brown et al. (1986). O sedimento obtido de $500 \mathrm{~mL}$ de cultura de C. pseudotuberculosis foi homogeneizado em $20 \mathrm{~mL}$ de solução salina e $0,2 \mathrm{~mL}$ de $10 \%$ de formalina, aquecido a $100^{\circ} \mathrm{C}$ por 20 minutos, e centrifugado. O material sedimentado foi lavado em solução salina duas vezes mais, e o sedimento final, adicionado de $0,4 \mathrm{~g} / \mathrm{L}$ de azida sódica. Foi prensado em um instrumento (prensa francesa) a pressão de 20.000 psi, para se tornar viscoso. Ao espectofotômetro, sob comprimento de onda de 540 mm, a diluição de 1:100 apresentou absorvância linear de 0,57 e a transmitância de $25 \%$. Trinta dias após a segunda vacinação, todos os caprinos foram desafiados, por via intradérmica, com $100 \mu \mathrm{L}$ contendo $4,2 \times 10^{3}$ unidades de colônias de C. pseudotuberculosis. O teste de pele foi realizado dez dias antes do desafio, uma semana, cinco e dez semanas após o desafio. Cada caprino foi inoculado por via intradérmica na base mediana ventral da cauda com $0,1 \mathrm{~mL}$ da diluição de 1:100. A pele foi higienizada com álcool a 70\% antes de cada inoculação. A leitura e a interpretação da reação alérgica foram realizadas 48 horas após a inoculação. A espessura da dobra da pele foi verificada usando-se um cutímetro de Hauptner e realizada antes da inoculação. O teste de Student foi utilizado para verificar a diferença significativa do diâmetro da reação dérmica entre os grupos vacinados e os grupos-controle.

\section{RESULTADOS E DISCUSSÃO}

Os caprinos não desenvolveram reações ao teste de pele depois das vacinações e antes do desafio. Após o desafio, todos os animais desenvolveram reações mensuráveis em resposta ao teste de pele. Os diâmetros da reação dérmica aumentaram 
do décimo dia após o desafio à quinta semana, e as medidas alcançaram o seu tamanho maior na décima semana. Pelo teste de Student, não houve diferença significativa $(\mathrm{p}<0,01)$ entre os grupos I (Tabela 1) e II (Tabela 2) e entre o grupo I e os dois grupos-controle (Tabela 3), na quinta e décima semana após a infecção. Os achados estão condizentes com os de Brown et al. (1986), que utilizaram células fragmentadas do C. pseudotuberculosis em um teste de pele e injetadas, a intervalos irregulares, em caprinos já infectados experimentalmente. Eles observaram que não houve reação dérmica ao teste antes do desafio. Entretanto, as respostas ao teste de pele aumentaram diretamente em relação à severidade da doença clínica. Neste trabalho, o teste de pele foi realizado para avaliar a imunidade celular em caprinos vacinados e desafiados, tendose observado que nenhum dos animais vacinados e os grupos-controle responderam ao teste de pele antes do desafio. Após o desafio, oito animais no grupo I apresentavam reação ao teste de pele, na primeira, quinta e décima semanas. No grupo II, havia nove animais que responderam na primeira semana; seis animais, na quinta, e oito animais, na décima semana após o desafio. Nos dois gruposcontrole, os dez animais reagiram como positivos na primeira, quinta e décima semanas. As reações foram mais proeminentes na décima semana, o que indica um desenvolvimento contínuo da resposta imunocelular. Não houve uma correlação aparente entre a severidade da doença e as reações de pele. Três animais com a doença disseminada apresentavam o diâmetro da reação de $1,8 \mathrm{~cm}, 1,9$ e $1,8 \mathrm{~cm}$, respectivamente, com média de $1,8 \mathrm{~cm}$, enquanto seis animais sem a presença de lesões demonstravam reações de $2,0,1,9,2,1,1,0,1,7$ e $1,2 \mathrm{~cm}$, com média de $1,6 \mathrm{~cm}$.

As reações ao teste de pele indicaram exposição prévia aos constituintes do agente da linfadenite caseosa, mas este experimento não indicou uma correlação quantitativa entre o nível de resistência dos animais à infecção. Os animais vacinados com

TABELA 1. Medidas de reação dermal induzidas em caprinos, em 48 horas, os quais foram vacinados com toxóide de acordo com o número do animal, com o período pós-vacinação, com o diâmetro da reação e com a espessura da pele na área da reação, nos animais do grupo $I^{1}$.

\begin{tabular}{|c|c|c|c|c|c|c|}
\hline \multirow[t]{2}{*}{$\begin{array}{l}\text { Número do } \\
\text { caprino }\end{array}$} & \multicolumn{2}{|c|}{$\begin{array}{l}1 \text { semana depois da } \\
\text { infecção }\end{array}$} & \multicolumn{2}{|c|}{$\begin{array}{l}5 \text { semanas depois da } \\
\text { infecção }\end{array}$} & \multicolumn{2}{|c|}{$\begin{array}{c}10 \text { semanas depois da } \\
\text { infecção }\end{array}$} \\
\hline & $\mathrm{D}$ & $\mathrm{E}$ & $\mathrm{D}$ & $\mathrm{E}$ & $\mathrm{D}$ & $\mathrm{E}$ \\
\hline 1 & 0,59 & 0,28 & 1,61 & 0,82 & 1,85 & 0,90 \\
\hline 2 & - & - & - & - & - & - \\
\hline 3 & 0,70 & 0,30 & 1,55 & 0,80 & 1,86 & 0,87 \\
\hline 4 & 0,68 & 0,28 & 1,50 & 0,70 & 1,98 & 0,81 \\
\hline 5 & 0,75 & 0,31 & 1,60 & 0,75 & 2,01 & 0,90 \\
\hline 6 & 0,90 & 0,31 & 1,62 & 0,79 & 1,94 & 0,92 \\
\hline 7 & - & - & - & - & - & - \\
\hline 8 & 0,75 & 0,30 & 1,65 & 0,75 & 2,00 & 0,87 \\
\hline 9 & 0,83 & 0,28 & 1,49 & 0,70 & 1,97 & 0,89 \\
\hline 10 & 0,89 & 0,30 & 1,53 & 0,72 & 2,05 & 0,89 \\
\hline Média & 0,76 & 0,30 & 1,57 & 0,75 & 1,96 & 0,88 \\
\hline Desvio-padrão & 0,11 & 0,01 & 0,06 & 0,05 & 0,07 & 0,03 \\
\hline Diferença entre & & & & & & \\
\hline grupos I e II & - & - & $\mathrm{p}<0,01$ & $\mathrm{p}<0,01$ & $\mathrm{p}<0,01$ & $\mathrm{p}<0,01$ \\
\hline $\begin{array}{l}\text { Diferença entre } \\
\text { grupos I e controle }\end{array}$ & - & - & $\mathrm{p}<0,01$ & $\mathrm{p}<0,01$ & $\mathrm{p}<0,01$ & $\mathrm{p}<0,01$ \\
\hline
\end{tabular}

${ }^{1}$ D: diâmetro, em centímetro da reação medida na superfície da pele; E: espessura, em centímetros, da pele, na área da reação (densidade do folheto dérmico). 
TABELA 2. Medidas de reação dermal induzidas em caprinos, em 48 horas, os quais foram vacinados com bacterina de acordo com o número do animal, com o período pós-vacinação, com o diâmetro da reação e com a espessura da pele na área da reação, nos animais do grupo II $^{1}$.

\begin{tabular}{|c|c|c|c|c|c|c|}
\hline \multirow[t]{2}{*}{$\begin{array}{l}\text { Número do } \\
\text { caprino }\end{array}$} & \multicolumn{2}{|c|}{$\begin{array}{l}1 \text { semana depois } \\
\text { da infecção }\end{array}$} & \multicolumn{2}{|c|}{$\begin{array}{l}5 \text { semanas depois } \\
\text { da infecção }\end{array}$} & \multicolumn{2}{|c|}{$\begin{array}{l}10 \text { semanas depois } \\
\text { da infecção }\end{array}$} \\
\hline & $\mathrm{D}$ & $\mathrm{E}$ & $\mathrm{D}$ & $\mathrm{E}$ & $\mathrm{D}$ & E \\
\hline 11 & 0,65 & 0,23 & - & - & 1,02 & 0,64 \\
\hline 12 & - & - & - & - & - & - \\
\hline 13 & 0,74 & 0,32 & - & - & - & - \\
\hline 14 & 0,81 & 0,28 & 0,89 & 0,38 & 0,98 & 0,49 \\
\hline 15 & 0,65 & 0,30 & 0,81 & 0,37 & 1,64 & 0,89 \\
\hline 16 & 0,72 & 0,32 & - & - & 1,75 & 0,69 \\
\hline 17 & 0,65 & 0,27 & 0,86 & 0,39 & 1,74 & 0,76 \\
\hline 18 & 0,48 & 0,15 & 0,91 & 0,40 & 2,05 & 0,98 \\
\hline 19 & 0,64 & 0,28 & 0,87 & 0,36 & 0,98 & 0,50 \\
\hline 20 & 0,71 & 0,31 & 0,89 & 0,38 & 1,48 & 0,78 \\
\hline Média & 0,67 & 0,27 & 0,87 & 0,38 & 1,46 & 0,72 \\
\hline Desvio-padrão & 0,04 & 0,05 & 0,03 & 0,01 & 0,41 & 0,17 \\
\hline $\begin{array}{l}\text { Diferença entre os } \\
\text { grupos I e II } \\
\text { Diferença entre os }\end{array}$ & - & - & $\mathrm{p}<0,01$ & $\mathrm{p}<0,01$ & $\mathrm{p}<0,01$ & $\mathrm{p}<0,01$ \\
\hline grupos II e controle & - & - & - & - & - & - \\
\hline
\end{tabular}

1 D: diâmetro, em centímetro da reação medida na superfície da pele; E: espessura, em centímetros, da pele, na área da reação (densidade do folheto dérmico).

TABELA 3. Medidas de reação dermal induzidas em caprinos, em 48 horas, os quais foram submetidos à inoculação de infusão de cérebro e coração (animais números 21 a 25) e com solução salina (animais números 26 a 30), de acordo com o número do animal, com o período pós-vacinação, com o diâmetro da reação e com a espessura da pele na área da reação, nos animais dos grupos III e IV 1 .

\begin{tabular}{|c|c|c|c|c|c|c|}
\hline \multirow[t]{2}{*}{$\begin{array}{l}\text { Número do } \\
\text { caprino }\end{array}$} & \multicolumn{2}{|c|}{$\begin{array}{l}1 \text { semana depois } \\
\text { da infecção }\end{array}$} & \multicolumn{2}{|c|}{$\begin{array}{c}5 \text { semanas depois } \\
\text { da infecção }\end{array}$} & \multicolumn{2}{|c|}{$\begin{array}{l}10 \text { semanas depois } \\
\text { da infecção }\end{array}$} \\
\hline & $\mathrm{D}$ & $\mathrm{E}$ & $\mathrm{D}$ & $\mathrm{E}$ & $\mathrm{D}$ & $\mathrm{E}$ \\
\hline & \multicolumn{6}{|c|}{ Grupo III } \\
\hline 21 & 0,60 & 0,31 & 0,91 & 0,41 & 1,80 & 0,81 \\
\hline 22 & 0,75 & 0,25 & 0,87 & 0,36 & 1,45 & 0,71 \\
\hline 23 & 0,58 & 0,28 & 0,81 & 0,31 & 1,67 & 0,78 \\
\hline 24 & 0,81 & 0,34 & 0,94 & 0,42 & 1,89 & 0,87 \\
\hline 25 & 0,48 & 0,25 & 0,85 & 0,38 & 1,58 & 0,68 \\
\hline \multicolumn{7}{|c|}{ Grupo IV } \\
\hline 26 & 0,51 & 0,21 & 0,81 & 0,35 & 0,92 & 0,31 \\
\hline 27 & 0,48 & 0,20 & 0,72 & 0,29 & 1,40 & 0,64 \\
\hline 28 & 0,52 & 0,18 & 0,85 & 0,31 & 1,20 & 0,56 \\
\hline 29 & - & - & - & - & 0,97 & 0,38 \\
\hline 30 & 0,42 & 0,20 & 0,74 & 0,22 & 1,28 & 0,54 \\
\hline Média & 0,54 & 0,24 & 0,82 & 0,33 & 1,41 & 0,67 \\
\hline Desvio-padrão & 0,10 & 0,05 & 0,06 & 0,06 & 0,28 & 0,19 \\
\hline
\end{tabular}

${ }^{1}$ D: diâmetro, em centímetro da reação medida na superfície da pele; E: espessura, em centímetros, da pele, na área da reação (densidade do folheto dérmico). 
toxóide apresentaram resposta mais significativa ao teste de pele após o desafio do que os vacinados com bacterina, o que sugere que o toxóide estimulou uma resposta imunocelular melhor que os da bacterina.

As reações inespecíficas observadas nestes animais talvez sejam devidas a diversos componentes celulares. O reagente utilizado neste experimento para o teste de pele era cru, ou seja, uma suspensão de células fragmentadas do C. pseudotuberculosis. Então, uma quantidade vasta de antígenos incluindo componentes da parede celular, citoplasma e organelas intracelulares estavam presentes nos imunócitos. Shukla et al. (1971), utilizando a tuberculina em caprinos e ovinos naturalmente infectados com C. pseudotuberculosis, observaram reação cruzada não específica, isto, provavelmente em decorrência de antígenos comuns da parede celular. A presença da exotoxina encontrada no citoplasma e em menor quantidade na parede celular desta bactéria (Hard, 1975; Brown et al., 1986) pode favorecer a reação local de Arthus, o que ficou confundido com a possibilidade de uma reação de hipersensibilidade. $\mathrm{O}$ antígeno purificado pode ser útil na avaliação da resposta imunológica em animais experimentais para observar o progresso da doença ou em diagnóstico de caprinos com linfadenite caseosa no campo (Hard, 1975; Langenegger et al., 1987).

\section{CONCLUSÕES}

1. É fundamental a purificação do antígeno para o teste de pele da linfadenite caseosa.

2. O uso do antígeno específico de C. pseudotuberculosis como teste de pele pode auxiliar no diagnóstico da linfadenite caseosa em caprinos e ovinos no campo.

3. O teste de pele com C. pseudotuberculosis é útil para verificar a imunidade mediada por células e detectar casos subclínicos em um rebanho.

\section{AGRADECIMENTOS}

Ao Collaborative Research Support Program/ Small Ruminant - (USAID) /University of
California, Davis, pelo apoio financeiro; e à Dra. Corrie C. Brown, pelo incentivo.

\section{REFERÊNCIAS}

ALVES, S.F. Immunokinetics of goats with $C$. ovis vaccination and infection. Davis: Univ. of California, 1988. 68p. M.Sc. Thesis.

BROWN, C.C.; OLANDER, H.J.; BIBERSTEIN, E.L.; MORSE, S.M. Use of a toxoid vaccine to protect goats against intradermal challenge exposure to Corynebacterium pseudotuberculosis. American Journal of Veterinary Research, v.47, n.5, p.1116$1119,1986$.

COSTA FILHO, G.A. Diagnóstico precoce da linfadenite caseosa de caprinos através da intradermo-reação. Anais da Universidade Federal Rural de Pernambuco, Recife, v.1, n.2/3, p.161-170, 1977/78.

HARD, G.C. Comparative toxic effect of the surface lipid of Corynebacterium ovis on peritoneal macrophages. Infection and Immunity, v.12, n.6, p.1439-1449, 1975.

LAAK, E.A. ter; BOSCH, J.; BIJL, C.G.; SCHREUDER, B.E.C. Double-antibody sandwich enzyme-linked immunosorbent assay and immunoblot analysis used for control of caseous lymphadenitis in goats and sheep. American Journal of Veterinary Research, v.53, n.7, p.1125-1132, 1992.

LANGENEGGER, C.H.; LANGENEGGER, J. Avaliação da sensibilidade alérgica da infecção por Corynebacterium ovis em caprinos. In: CONGRESSO BRASILEIRO DE MEDICINA VETERINÁRIA, 19., 1984, Belém. Anais... Belém: Sociedade Brasileira de Medicina Veterinária, 1984. p.120-340.

LANGENEGGER, C.H.; LANGENEGGER, J.; COSTA, S.G. Alérgeno para o diagnóstico da linfadenite caseosa em caprinos. Pesquisa Veterinária Brasileira, v.7, n.2, p.27-32, 1987.

LEAMASTER, B.R.; SHEN, D.T.; GORHAM, J.R.; LEATHERS, C.W.; WELL, H.D. Efficacy of Corynebacterium pseudotuberculosis bacterin for the immunologic protection in sheep against development of caseous lymphadenitis. American Journal of Veterinary Research, v.48, n.5, p.869-872, 1987.

Pesq. agropec. bras., Brasília, v.34, n.7, p.1313-1318, jul. 1999 
MACKANESS, G.B. The monocyte in cellular immunity. Seminars in Hematology, v.7, n.2, p.172-184, 1970.

RENSHAW, H.W.; GRAFF, V.P.; GATES, N.L. Visceral caseous lymphadenitis in thin ewe syndrome: isolation of Corynebacterium, Staphylococcus, and Moraxella spp. from internal abscesses in emaciated ewes. American Journal of Veterinary Research, v.40, n.8, p.1110-1114, 1979.

SHUKLA, R.; NATH, N.; SINGH, G. Observations on nonspecific reactions to tuberculin in sheep and goats with Corynebacterium ovis. Experientia, v.27, n.2, p.204-205, 1971 